\author{
P. Gille, M. Mühlberg, L. Parthier, P. Rudolph \\ Humboldt-Universität zu Berlin, Sektion Physik, Bereich Kristallographie
}

\title{
Crystal Growth of PbTe and (Pb, Sn)Te by the Bridgman Method and by THM
}

\begin{abstract}
Synthesis and growth of $\mathrm{PbTe}$ and $(\mathrm{Pb}, \mathrm{Sn}) \mathrm{Te}$ single crystals by the Bridgman method and by the Travelling Heater Method (THM) from Te-rich solutions are described. It is to be seen from comparative investigations that seeded THM growth reproducibly provides oriented single-crystalline ingots free of low-angle grain boundaries and with etch pit densities of $8-12 \times 10^{4} \mathrm{~cm}^{-2}$. All the materials were p-type with carrier eoncentrations from 1 to $2 \times 10^{18} \mathrm{~cm}^{-3}$.
\end{abstract}

Проведены синтез и кристаллизация монокристаллов $\mathrm{PbTe}$ и (Pb, Sn)Te методами Бриджмена и движуцегося нагревателя из раствора-расплава, обогащенного теллуром. Сравнительный анализ показывает, что метод движущегося нагревателя из затравки позволяет получить воспроизводимые ориентированные монокристалли ческие слимки без малоугловых границ и с плотностью ямок травления $8-12 \times 10^{4} \mathrm{~cm}^{-2}$. Все образцы р-типомп роводимости. Концентрация дырок составляет $1-2 \times 10^{18} \mathrm{~cm}^{-3}$.

\section{Introduction}

$\mathrm{A}^{\mathrm{IV}} \mathrm{B}^{\mathrm{VI}}$ semiconducting compounds are used in preparing injection diode lasers with emission wave length larger than $3 \mu \mathrm{m}$, opening new ways in infrared spectroscopy. A wide field of applications arises from ultrahigh-resolution gas spectroscopy (HINKLEY, Kelley; Hinkley; BUTler, SAMple), highly sensitive trace gasmonitoring (Hill, Montgomery), isotope analysis (NILL; Lehmann et al.), isotope separating laser technique (JENSEN et al.), oxygen determination in silicon crystals (OHSAWA et al.), and prospective development in IR light guidance fiber technology with an attenuation of $10^{-2} \mathrm{~dB} / \mathrm{km}$ with $\lambda=4-6 \mu \mathrm{m}$. (DIANov)

The most important $\mathrm{A}^{\mathrm{IV}} \mathrm{B}^{\mathrm{VI}}$ narrow-gap materials are $\mathrm{PbTe}$, $\mathrm{PbSe}$ and $\mathrm{PbS}$ which form solid alloys and cover a wide range of tunable wavelengths by additionally replacing lead by tin atoms.

The deposition of thin epitaxial films of $\mathrm{Pb}_{1-x} \mathrm{Sn}_{x} \mathrm{Te}(6-30 \mu \mathrm{m}), \mathrm{PbS}_{1-x} \mathrm{Se}_{x}$ (4.3 to $8.7 \mu \mathrm{m})$ and $\mathrm{Pb}_{1-x} \mathrm{Sn}_{x} \mathrm{Se}(8-30 \mu \mathrm{m})$ on single-crystalline substrates of $\mathrm{A}^{\mathrm{IV}} \mathrm{B}^{\mathrm{VI}}$ compounds provides the active layer. Reviews on the technology of infrared devices and special problems with $\mathrm{A}^{\mathrm{IV}} \mathrm{B}^{\mathrm{VI}}$ materials have been given by MeLNGaILIs and Harman; Hesse and Preter, Premer, and Kobayashi et al.; Hesse, and Herrmann et al.

In the study presented here we are concerned with various problems involved in crystal growth for the aim of $\mathrm{A}^{\mathrm{IV}} \mathrm{B}^{\mathrm{VI}}$ infrared technology.

The materials under consideration are characterized by a series of unfavourable physico-chemical and crystallographic properties which complicate the feasibility of production technologies for single crystals and devices. 
For a longer time we examined the possibilities of growing perfect $\mathrm{PbTe}$ crystals from the melt and from solution in closed crucibles to avoid problems arising from vapour dissociation, stoichiometry and encapsulation. It was the purpose of our crystal growth experiments to produce substrate naterials for $\mathrm{PbTe} / \mathrm{Pb}_{1-x} \mathrm{Sn}_{x} \mathrm{Te}$ heterostructure lasers. Suitable growth conditions could be found.

\section{Basic problems}

\subsection{Phase diagram}

The phase diagram of the $\mathrm{Pb}$-Te system with particular emphasis on the $\mathrm{PbTe}$ stability region (MüHLBERG, HEsse) is shown in Figure 1.

The congruent melting point $\left(924^{\circ} \mathrm{C}\right)$ does not coincide with the stoichiometric line, but differs by a Te excess of 0.016 at \% (STRAuss). This is essential if single crystal growth is to be performed from the melt, e.g. with normal freezing by the Bridgman method. Because of the strongly retrograde course of the solidus line precipitation of the excess component occurs during cooling the crystal which has grown near melting point temperatures. Besides a difficult process of influencing nucleation of PbTe (KAnter, Sidorov) and a very low critical shear stress of dislocation generation (JockEL), it is these precipitates which much cause the formation of dislocations and affect the reliability of divices. For that reason, it is not possible to grow high-perfect $\mathrm{PbTe}$ single crystals by the vertical Bridgman method, which are absolutely free of low-angle grain boundaries (MüHLBERG). Nevertheless, because of the simple technology and relatively high crystal growth rates there is widespread interest for the Bridgman technique in basic research on $\mathrm{PbTe}$.

New possibilities result from the crystallization from strongly nonstoichiometric melts, i.e. from solutions of $\mathrm{PbTe}$ and an excess component as the solvent ( $\mathrm{Pb}$ or $\mathrm{Te}$ ). Because of higher solubilities and a nearly straight liquidus line, particularly the Te-rich side of the PbTe system is suitable for solution growth of PbTe (Fig. 1). Besides a much lower crystallization temperature and vapour pressure, and an essentially higher critical shear stress of dislocation generation at decreased temperatures (TILLER 1963), the reduced width of the PbTe stability region and the resulting lower carrier concentration are the main advantages of crystal growth from solution. On account of the use of an oriented seed and the constant volume of the solution zone, the travelling heater method (THM) has proved the most promising solution growth technique for the compound under consideration. As a special technique of zone melting THM enables a purification of the grown material. With respect to the perfection, THM-grown PbTe single crystals have shown to be superior to those obtained by the Bridgman method. The main drawback of the travelling heater method is the by one or two orders of magnitude lower growth rate which results from the diffusion-defined transport. Reviews on this method have been given by WOLFF and Mlavsky, Benz and Bauser.

\subsection{Theoretic aspects of crystal growth rates}

In crystal growth from a nonstoichiometric melt, i.e. in the presence of an excess component, material transport through the liquid phase must be considered a basie problem, usually requiring closer limits of maximum growth rates than the conduction of heat of crystallization. TILLER et al. gave the condition to prevent constitutional supercooling which in connection with material parameters depends on the ratio of the temperature gradient in front of the interface and the rate of solidification. It 
has proved a good estimation in the absence of convection and has been further adapted to special growth conditions by many authors (e.g. Tiller 1968; Coriell et al.). Crystal growth by the Bridgman method with slight deviations from stoichiometry on the one hand and THM growth on the other hand can be seen as two extreme cases of the growth from nonstoichiometric melts which are much different in the content of an excess component. Accordingly, the constitutional supercooling criterion gives different information on maximum growth rates of the two methods. Most decisive reasons result from the positions in the phase diagram, i.e. from temperatures of solidification and the corresponding saturation solubilities of the excess component in the liquid phase. Regardless of the relatively uncertain knowledge of temperaturedepending diffusion coefficients of the liquid (Karklina, KovalC̈IK; Clakk et al.), an estimation for the chosen growth conditions gives a THM crystal growth rate which is approximately by one order of magnitude lower than that for the Bridgman method. In principle, Triboulet et al. also mentioned problems in estimating THM growth rates from the constitutional supercooling criterion. It provided rates of solidification which were much higher than those proved by experiments. Formulae for THM growth velocities like those obtained with calculations of diffusive material transport in liquid phase epitaxy (LoNG et al.) and applied to the mechanism of THM (BENZ, BAUSER) do describe diffusion correctly but make no sense with respect to technological questions. They need the actual concentrations at both liquid solid interfaces which for their part depend on the heater velocity.

\section{Performance of experiments}

\subsection{Synthesis of compounds}

Ingots of lead, tin and tellurium, all of $5 \mathrm{~N}$ quality, were used without further metallurgical purification. All steps of the synthesis were carried out in silica ampoules and tubes which had been purified with a mixture of $\mathrm{HF}: \mathrm{HNO}_{3}=1: 10$ and heated at temperatures of about $1000{ }^{\circ} \mathrm{C}$ in a high vacuum for 15 hours before. For the aim of separating oxidic components the elements were put in silica tubes with a hole at the bottom of about $1 \mathrm{~mm}$ in diameter. In a $50 \mathrm{kPa}$ pure hydrogen atmosphere the molten metals flowed through it into the ampoule leaving behind oxidic impurities. Tellurium, purified in the same manner, was cleft into pieces and filled in, according to the mass of $\mathrm{Pb}$ and $\mathrm{Sn}$, respectively. After evacuating (about $1 \mathrm{mPa}$ ) and fusing the loaded ampoule, the reaction took place in a furnace at about $600{ }^{\circ} \mathrm{C}$, followed by 24 hours at $1000{ }^{\circ} \mathrm{C}$ to homogenize the melt. The composition with respect to the metal/tellurium ratio was chosen to be either dystectic (50.016 at\% (STRAuss)) or with a slightly larger excess of Te. Normal freezing by the Bridgman method of Te-rich synthesized material in the reaction ampoule provided a homogeneous $\mathrm{p}$-type $\mathrm{Pb}$ Te ingot and an eutectic mixture of $\mathrm{PbTe}$ and $\mathrm{Te}$, separated by a sharp, plane boundary. With a $\mathrm{Pb}$-richer than the dystectic composition the ingot was inhomogeneous involving $\mathrm{n}$ type as well as p-type sections and $\mathrm{Pb}$ inclusions of about 50 to $100 \mu \mathrm{m}$ (Mü HLBERG).

\subsection{Bridgman method}

The single crystal growth after the Bridgman method took place in a four-zonefurnace (MüHLBERG). Generally, a temperature gradient of about $30 \mathrm{Kcm}^{-1}$ was used. The temperature in the upper furnace was $1000{ }^{\circ} \mathrm{C}$ maximum, in the lower furnace 
about $800{ }^{\circ} \mathrm{C}$. The velocities of the ampoules lay between 0.3 and $2 \mathrm{~mm} \mathrm{~h}^{-1}$, usually at $1 \mathrm{~mm} \mathrm{~h}^{-1}$. After ensured grow th the ampoules cooled down at a rate of about 10 to $20 \mathrm{~K} \mathrm{~h}^{-1}$. For further information see Table 1.

\subsection{Travelling heater method}

Crystal growth by the travelling heater method requires a feed material that corresponds to the single crystal to grow with respect to the chemical composition and geometry. Fashioning was undertaken by a normal freezing procedure of synthesized $\mathrm{PbTe}$ or $(\mathrm{Pb}, \mathrm{Sn}) \mathrm{Te}$ melts in a $12 \mathrm{~mm}$-diameter silica ampoule. Since there is no demand for structural perfection of the cast ingot at all, higher growth rates than described in the Bridgman method could be employed, though constitutional supercooling might appear. Hollows or cavities must not occur.

The usual THM arrangement consisted of a single-crystalline seed, a solvent zone (Te) and a source material, all of the same diameter $(12 \mathrm{~mm})$ and enclosed by a silica tube which had to suit the seed very well to prevent the liquid zone from leaking out, and to allow the seed to extend during the heating process, on the other hand. The cylindrical Te zone of the wished lenght was cut out of a cast ingot. The length of the used solvent zone, i.e. the mass of Te, follows from the solubility in the Te-rich part of the $\mathrm{Pb}-\mathrm{Te}$ system, the employed temperature at the liquid solid phase boundaries during the growth, and the axial temperature distribution of the resistance heater. In the crystal growth described here, there was used a $4.5 \mathrm{~mm}$ long Te zone (i.e. $3.2 \mathrm{~g} \mathrm{Te}$ with a diameter of $12 \mathrm{~mm}$ ) which corresponds to a solution zone of about $10 \mathrm{~mm}$ at a growth temperature of $550{ }^{\circ} \mathrm{C}$. The surfaces of the seed, zone and feed to contact each other were mechanically polished after spark-erosive cutting perpendicular to the cylindrical axis. On principle, a preparation by chemical means was avoided.

The expense of preparing a THM arrangement was much lower, if no seed at all was used and a spontaneous nucleation in the conical tip of a crucible took place. For this purpose the wished amount of the liquid Te zone was filled into the crucible before, as described with the synthesis.

In the two cases the prepared crystal growth arrangement was placed within a silica ampoule which was fused or otherwise closed after having been evacuated and filled with a $50 \mathrm{kPa}$ argon atmosphere. The inert gas pressure is thought to prevent the solution zone from evapourating tellurium or at least to reduce this process. The ampoule was moved through the resistance heater by a synchronous motor with speed reducing units at a rate of $2 \mathrm{~mm} \mathrm{~d}^{-1}$. According to the length of the used source ingot, it took the crystals up to two months to grow.

\subsection{Surface preparation of $\mathrm{PbTe}$ and $(\mathrm{Pb}, \mathrm{Sn})$ Te samples}

The Brigdman and THM crystals were cut into pieces by a spark-erosive_saw. By several polishing cycles with argillaceous earth of different granulation and by a subsequent chemical lap polishing in a mixture of $\mathrm{A}: \mathrm{B}=3: 2(\mathrm{~A}=0.8 \mathrm{~mol}$ aqueous solution of potassium hexacyanoferrat (III); $\mathrm{B}=0.1 \mathrm{~mol}$ aqueous solution of sodium hydroxide and $4 \mathrm{vol} \%$ glycerol) (BREITsameter et al.) the damaged layer of about 200 to $350 \mu \mathrm{m}$ was moved after sawing. By means of an electrolytic etching method described by NoRR the grain or single-crystalline structure could be made visible, while the etching procedure of OHtsukI et al. provided well marked etch pits on (100)oriented surfaces.

Moreover, the low-angle grain boundary substructure was also analyzed by X-ray topographic means (BERGER). 


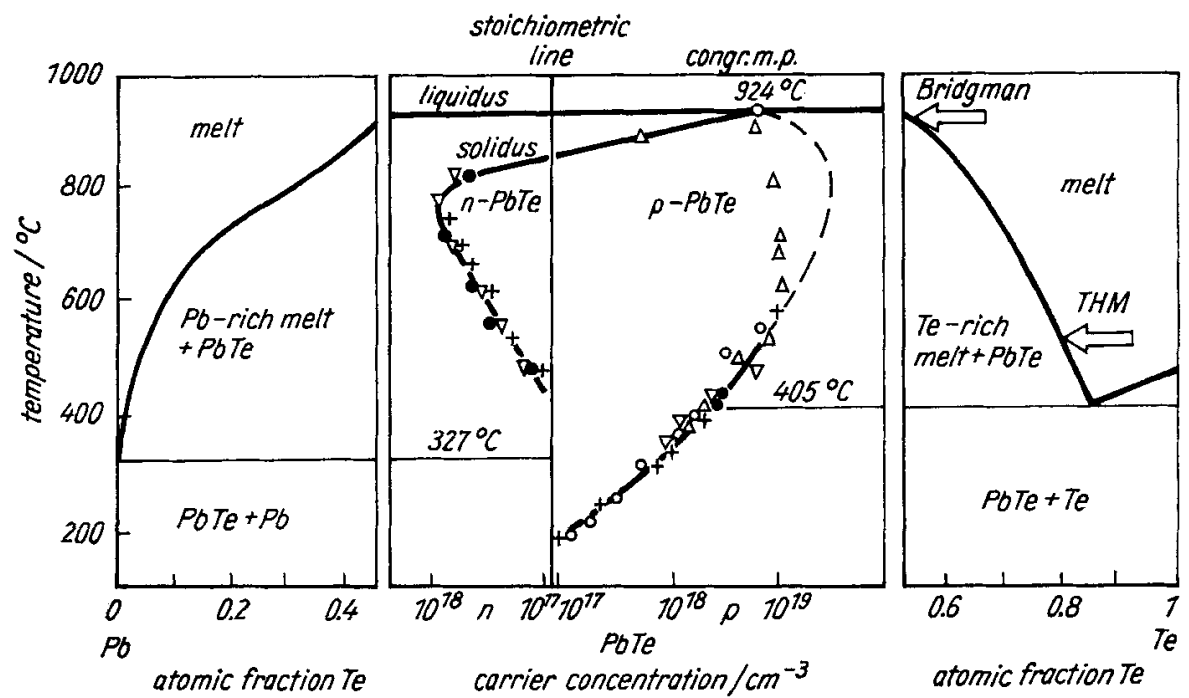

Fig. 1. Phase diagram of the Pb-Te system and the PbTe stability region (MüHLBERG, Hesse)

\section{Results}

\subsection{General remarks}

Generally, single crystals reproducibly grew only with the travelling heater method if a single-crystalline seed had been used. With spontaneous nucleation in the Bridgman method or unseeded THM either single crystals or crystals with a large-grained structure could be obtained. Tapering of the lower end of the Bridgman ampoule $(4 \mathrm{~mm}$ diameter over a length of about $40 \mathrm{~mm}$; see Tab. 1) and a carbon-coating of the inner walls of the ampoule resulted in a positive influence on nucleation.

Thermal decomposition of heptane at $900^{\circ} \mathrm{C}$ gave a porous but stable coating which is though to favour heterogeneous nucleation and to reduce the PbTe melt's ability to supercool up to $50 \mathrm{~K}$ (KANTER, SIDORov). Crystals grown in uncoated ampoules provided polycrystalline and porous first-to-freeze sections (see Fig. 2) which we assume is due to a sudden solidification of the heavily supercooled PbTe melt.

$\mathrm{PbTe}$ and $(\mathrm{Pb}, \mathrm{Sn}) \mathrm{Te}$ erystals grown by the Bridgman method show smooth surfaces or facets. THM-grown ingots have smooth surfaces, too, on which small stripes perpendicular to the growth direction are visible.

The shape of the solid liquid interface in THM is to be influenced by taking different amounts of the Te solvent, i.e. by different effective zone lengths in a given temperature profile or by changing the heater power, i.e. the maximum temperature. A growing interface which is convex with respect to the liquid accounts favourably for the structural perfection of the growing crystal and can be achieved with an actual solution zone somewhat smaller than the effective heater length (BELL; BEnz, Müller) (see Fig. 3).

After entirely consuming the source material an eutectic $\mathrm{PbTe} / \mathrm{Te}$ mixture solidifies at the end of the THM crystal growth run. In the Bridgman method the use of a nonstoichiometric melt can give some information on the shape of the solid-liquid interface. A Te-rich composition of the melt yields with the noted growth conditions (Tab. 1) 
Table 1

Some experimental parameters and properties of PbTe crystals grown by the Bridgman method and THM

\begin{tabular}{|c|c|c|}
\hline & $\begin{array}{c}\text { crystals grown by } \\
\text { the Bridgman method }\end{array}$ & crystals grown by THM \\
\hline $\begin{array}{l}\text { diameter of crystals } \\
(\mathrm{mm})\end{array}$ & $12-18$ & 12 \\
\hline length of crystals $(\mathrm{mm})$ & up to 100 & up to 100 \\
\hline $\begin{array}{l}\text { arrangement } \\
\text { of ampoules (mm) }\end{array}$ & $\phi_{i}=4 \iint \approx 40$ & 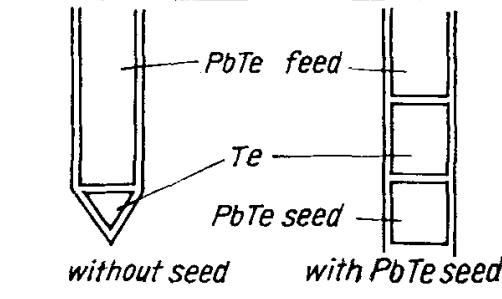 \\
\hline $\begin{array}{l}\text { temperature of } \\
\text { cristallization }\left({ }^{\circ} \mathrm{C}\right)\end{array}$ & 924 & about 550 \\
\hline $\begin{array}{l}\text { temperature gradient } \\
(\mathbf{K} / \mathrm{cm})\end{array}$ & about 30 & about 100 \\
\hline $\begin{array}{l}\text { crystal growth } \\
\text { rate }(\mathrm{mm} / \mathrm{h})\end{array}$ & $0.3-2$ & 0.08 \\
\hline erystallinity & $\begin{array}{l}\text { single erystals with } \\
\text { low-angle grain boun- } \\
\text { daries and crystals } \\
\text { with large-grained } \\
\text { structure }\end{array}$ & $\begin{array}{l}\text { single crystals without low-angle } \\
\text { grain boundaries (if using a seed) } \\
\text { often crystals with large-grain } \\
\text { structure (without seeding) }\end{array}$ \\
\hline $\operatorname{EPD}\left(\mathrm{cm}^{-2}\right)$ & $\approx 10^{6}$ & $\approx 10^{5}$ \\
\hline $\begin{array}{l}\text { as-grown } \\
\text { conductivity }\end{array}$ & $\begin{array}{l}\mathrm{p} \text { (homogeneous if } \\
\text { slightly Te-rich melt) }\end{array}$ & P (homogeneously) \\
\hline $\begin{array}{l}\text { as-grown carrier } \\
\text { concentration }\left(\mathrm{cm}^{-3}\right)\end{array}$ & $2-3 \times 10^{18}$ & $1-2 \times 10^{18}$ \\
\hline $\begin{array}{c}\text { Hall mobility }\left(\mathrm{cm}^{2} / V \mathrm{~s}\right) \\
77 \mathrm{~K} \\
300 \mathrm{~K}\end{array}$ & $\begin{array}{r}15000-20000 \\
750-1000\end{array}$ & $\begin{array}{c}\approx 20000 \\
800-1000\end{array}$ \\
\hline
\end{tabular}

a nearly plane boundary between the PbTe crystal and the eutectic rest. On the other hand, a clear concave interface (see Fig. 4) results from a metal-rich melt. The cause of it could be seen among other things in the extremely different thermal conductivities of metal-rich and Te-rich PbTe melts, respectively. Although there is a shortage of thermal conductivity data of the materials under consideration, the corresponding electric conductivities allow this conclusion. GLAzov et al. stated a nearly constant electric conductivity of liquid $\mathrm{PbTe}$ with an increasing Te content, whereas a $\mathrm{Pb}_{0.55}$ $\mathrm{Te}_{0.45}$ melt already doubles the coefficienz.

\subsection{Structural perfection}

Generally, crystal growth in a crucible causes a relatively high dislocation density $\left(\geq 10^{3} \mathrm{~cm}^{-2}\right)$. Moreover, dislocations within the already grown crystal can interact, 


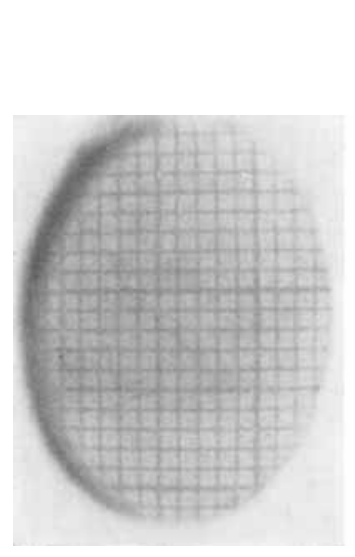

single crystal
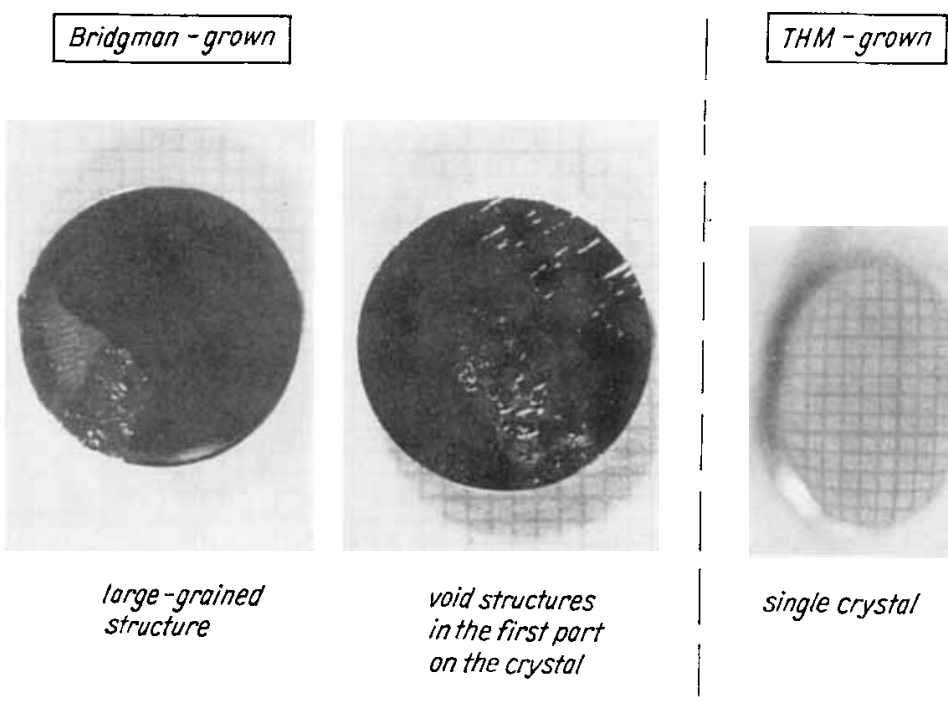

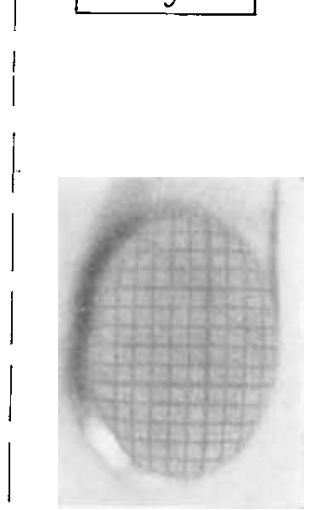

single crystol

Fig. 2. Comparison between the general appearance of Bridgman-grown and TIIM-grown slices

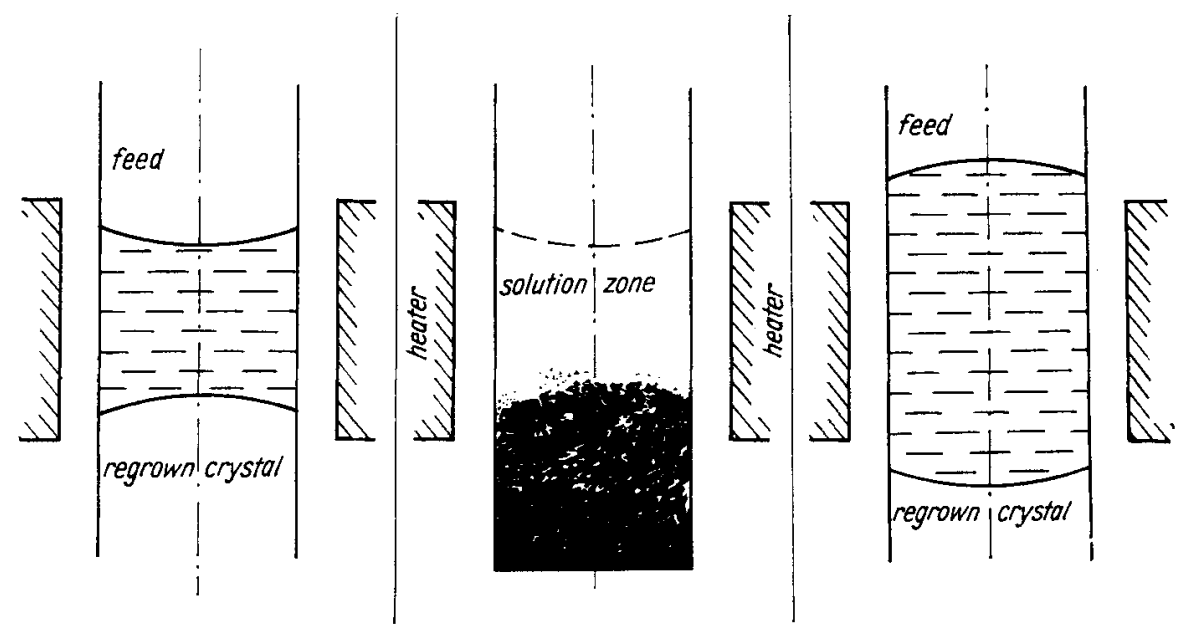

Fig. 3. Variation of the shape of the THM crystallization front with different amounts of solvent (BELL) and the experimental result (middle part)

depending on a lot of materials properties and thermal conditions during and after the solidification process. The dislocations move to low-angle grain boundary substructures which are more favourable with respect to the energetic state (TILLER 1963).

These substructures are arranged along the crystal growth direction and have a length of about 15 to $20 \mathrm{~mm}$ with a diameter of some tenths of a millimetre up to some millimetres. Low-angle grain boundaries separate these sections which are disoriented by angles between some minutes of are and about $5^{\circ}$.

MÜHLBERG described the appearance of low-angle grain boundary substructures in Bridgman-grown PbTe crystals in detail. Whereas the frequency of low-angle grain 


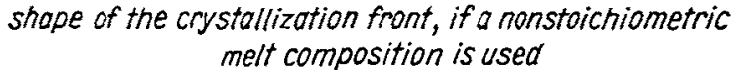

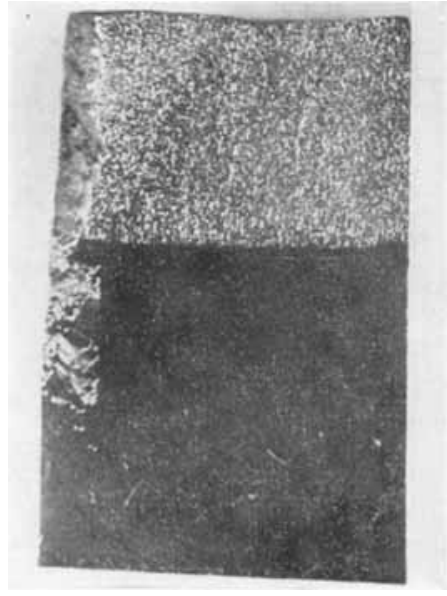

PbTe +5 at. $\%$ excess of $\mathrm{Te}$

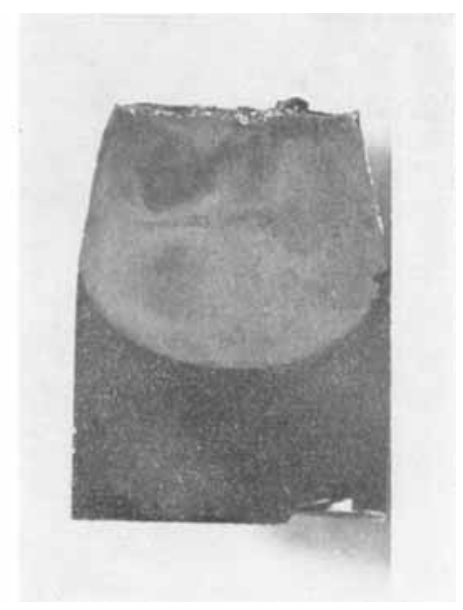

PbTe +5 at. \%

excess of $P Q$

Fig. 4. Influence of different melt compositions on the shape of the crystallization front of Bridgman-grown crystals

boundaries in crystals grown by the Bridgman method at most can be reduced, solution growth by THM provides PbTe single crystals which are free of these imperfections (GILLE, RUDOLPH). Much lower growth temperatures (about $550{ }^{\circ} \mathrm{C}$ contrary to about $900{ }^{\circ} \mathrm{C}$ with the Bridgman method) strongly restrict the mobility of dislocations. Moreover, it can be estimated that by reason of smaller critical resolved shear stress the total number of dislocations formed during solidification in THM crystals is essentially lower. The average etch pit density in Bridgman-grown PbTe crystals amounts about $10^{6} \mathrm{~cm}^{-2}$ contrary to $1-2 \times 10^{5} \mathrm{~cm}^{-2}$ in THM crystals (EPD of the best crystals about $\left.8 \times 10^{4} \mathrm{~cm}^{-2}\right)$. Whereas the axial distribution of etch pits in PbTe ingots grown by THM is nearly constant, the tech pit density in the Bridgman crystals varies between $5 \times 10^{5} \mathrm{~cm}^{-2}$ in the middle part and $1-2 \times 10^{6} \mathrm{~cm}^{-2}$ in the first-freeze section and in the end of the ingot. The weak interaction of the crystals with the crucible walls is to be seen from X-ray topographic examinations (Fig. 5) as well as determination of etch pit densities. The frequency of low-angle grain boundaries and etch pits does not increase in the immediate vicinity of the ampoule wall.

\subsection{Te precipitates in $\mathrm{PbTe}$}

The axial distribution with respect to the $\mathrm{Pb} / \mathrm{Te}$ ratio was determined by measuring the carrier concentration. Because of the strong temperature dependence of the breadth of the stability region, a variation of the carrier concentration across the length of Bridgman-grown crystals should be expected, if a segregation consistent with the solidus line of the phase diagram is assumed, i.e. if no precipitates occur. Conversely, measuring the carrier concentration revealed a relatively constant distribution over the axial position in the crystals grown by both methods (see Tab. 1). This was one of the reasons for carrying out electron microscopic investigations on possible precipitates in PbTe. It is well known of $\mathrm{ZnTe}$ (Jordan, Derick) and PbSe (Abrams, TaU- 


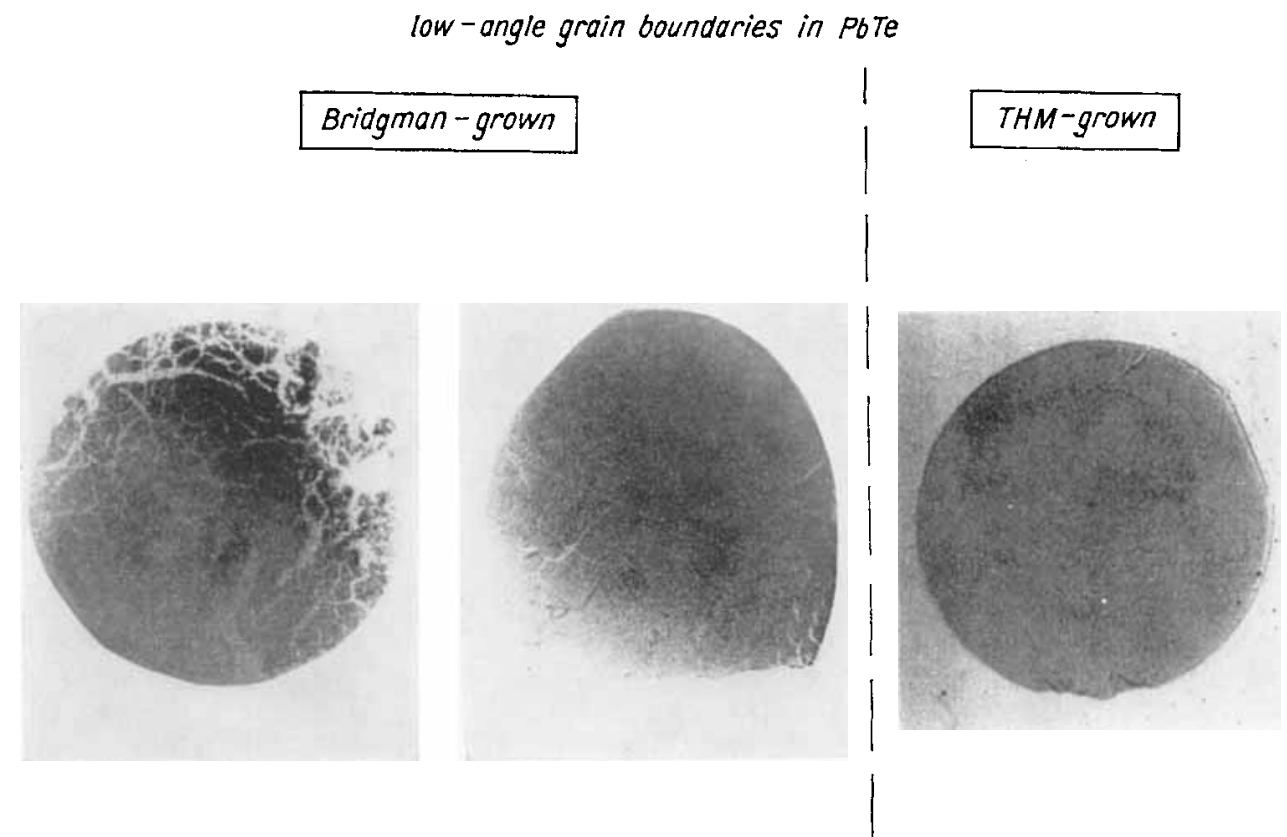

Fig. 5. Comparison between X-ray topographs of Bridgman-grown and THM-grown PbTe slices (12 $\mathrm{mm}$ in diameter)

BER) that compound semiconductors with a strongly temperature-depending retrograde course of the solidus line contain precipitates of the excess component. Transmission electron microscopic studies done by MühlberG, Hesse confirmed the assumption of the formation of precipitates from Te excess during cooling the $\mathrm{PbTe}$ crystal after the Bridgman growth. Two kinds of Te precipitates could be detected: (i) needle-like precipitates (diameter: 3 to $6 \mathrm{~nm}$, length: 10 to $20 \mathrm{~nm}$, density: about $2 \times 10^{16} \mathrm{~cm}^{-3}$ ) which are aligned parallel to $\langle 100\rangle$ and (ii) spheroidal precipitates (diameter: 5 to $8 \mathrm{~nm}$, density: about $2 \times 10^{15} \mathrm{~cm}^{-3}$ ). These investigations support the diffusion-defined precipitation theory suggested by HAM which among other things causes a constant distribution of the carrier concentration over the axial position of the PbTe crystals. Further precipitation studies with THM grown material will be done.

\subsection{Sn segregation in $(\mathrm{Pb}, \mathrm{Sn}) \mathrm{Te}$ crystals}

According to the difference of slope of the solidus and liquidus line in the pseudobinary $\mathrm{Pb}$ 'Te-SnTe system in crystal growth of $\mathrm{Pb}_{1-x} \mathrm{Sn}_{x} \mathrm{Te}(x \lesssim 0.2)$ from the melt a distribution coefficient of $k_{0} \approx 0.6$ is to take into account which further increases with an increasing Sn content (Wagner, Willardson; Calawa et al.). Therefore, in normal freezing experiments a distinct segregation is to be expected. The distribution of SnTe over the length of a Bridgman-grown crystal yielded under the above noted conditions a satisfactory correspondence with the theoretic normal freezing function. Mole fractions $x$ of the solid solutions were determined by X-ray measurements of the lattice parameters which had been proved to obey Vegard's law (BIs, Dixon).

In the crystal growth of $\mathrm{Pb}_{1-x} \mathrm{Sn}_{x} \mathrm{Te}$ by THM, on principle, the zone melting distribution equation is valid, provided the original composition of the solution zone, which is different from that of the source material, is taken into account. 
In the Te-rich corner of the ternary $\mathrm{Pb}-\mathrm{Sn}-\mathrm{Te}$ system the distribution coefficient $k_{0}$ considering the $\mathrm{Pb} / \mathrm{Sn}$ ratio in the crystal and in the liquid zone, respectively, is almost independent of the temperature of solidification (LAUGIER). For that reason a THM growth run from a Te-rich zone using a homogeneous feed reproduces the homogeneous distribution with the only exception of the initial part known from zone melting. Figures $6 \mathrm{a}$ and $\mathrm{b}$ show the $\mathrm{Sn}$ segregation in THM crystals resulting from Bridgman-grown and quenched feeds, respectively.
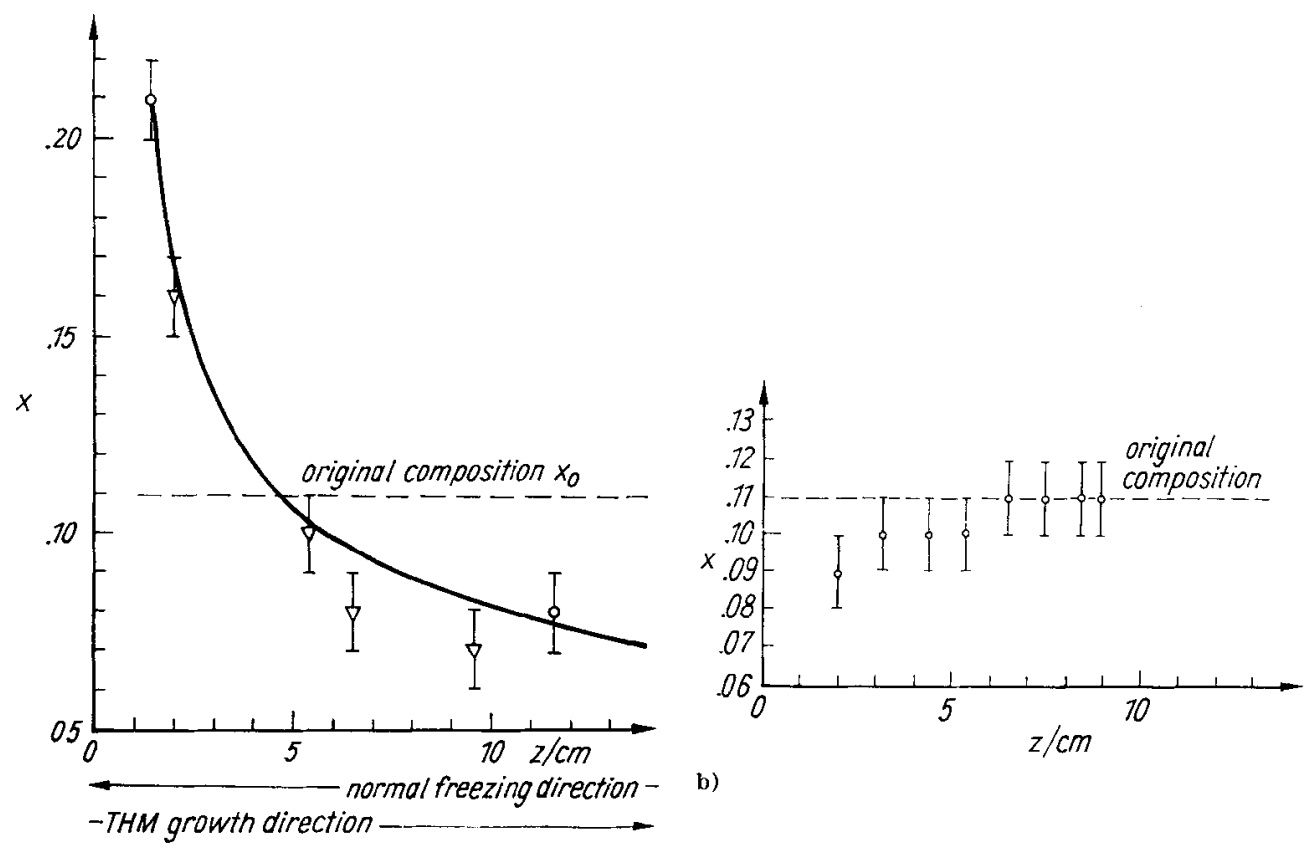

a)

Fig. 6a. Sn segregation in THM-grown $\mathrm{Pb}_{1-x} \mathrm{Sn}_{x}$ Te crystals prepared from Bridgman-grown sources $O$ grown by normal freezing, $\nabla$ grown by THM with a normal freezed source, theoretic normal freezing function with $k=0.65$

Fig. $6 \mathrm{~b}$. Sn segregation in THM-grown $\mathrm{Pb}_{1-x} \mathrm{Sn}_{x} \mathrm{Te}$ crystals prepared from quenched sources

\section{Conclusions}

We have grown $\mathrm{PbTe}$ and $(\mathrm{Pb}, \mathrm{Sn}) \mathrm{Te}$ by the vertical Bridgman technique from the melt and by the travelling heater method from a Te-rich solution zone. Both methods have proved suitable to provide substrate material for infrared devices. Seeded THM growth prevents substantial drawbacks of the Bridgman method like spontaneous nucleation, large-grained structures and the occurence of low-angle grain boundaries. The etch pit density could be reduced by one order of magnitude to about $10^{5} \mathrm{~cm}^{-2}$.

\section{References}

Abrams, H., Tauber, R. N.: Metallurg. Trans. 1, 175 (1970)

BkLL, R. O.: J. Electrochem. Soe. 121, 1366 (1974)

Benz, K. W., Bauser, E. : in: Crystals: growth, Properties and Applications, Vol. 3, pp. 8, Ed. by H. C. Fre Yhar Dt, Berlin, Heidelberg, New York, 1980

Benz, K. W., Müllen, G.: J. Cryst. Growth 46, 35 (1979) 
Berger, H.: Kristall u. Technik (Crystal Res. \& Technol.) 12, K 65 (1977)

Bis, R. F., Dixon, J. R.: J. Appl. Physies 40, 1918 (1969)

Breitsameter, B., Löwe, H., Hartmann, W., Engel, A.: DDR.Wirtschaftspatent, WP 142830,1977

Butler, J. F., Sample, J. O.: Cryogenics 17, 661 (1977)

Calaw a, A. R., Harman, T. C., Finn, M., Youtz, P.: Trans. Met. Soc. AlME 242, 374 (1968)

Clark, I. O., Fripp, A. L., Deblam, Jr. W. J., Crouch, R. K., Brewer, W. D. : J. Electrochem. Soe. 130, 164 (1983)

Coriell, S. R., Hurle, D. T. J., Sek ERka, R. F.: J. Cryst. Growth 32, 1 (1976)

Dianov, E. M.: Kvantovaja elektronika 9, 2109 (1982)

Gille, P., Rudolph, P.: J. Cryst. Growth 64, 613 (1983)

Glazov, V. M., Ciževskaja, S. N., Glagoljeva, N. N.: Židkie poluprovodniki, Moskva 1967

Ham, F. S.: J. Phys. Chem. Solids 6, 335 (1958)

Herrmann, K., Rudolph, P., Albers, C.: Wissensch. Zeitschr. Humboldt-Universität zu Berlin, Math.-Nat. R. XXX, 1 (1981)

Hesse, J.: Elektronik (1980), 1, 52

Hesse, J., Preicr, H. : in : Festkörperprobleme, Vol. 15, pp. 229, Ed. by H. J. Queisser, Braunschweig 1975

Hili, J. C., Montgomer y, G. P.. Appl. Opties 15, 748 (1976)

HIN KLEX, E. D.. Optoelectronics 4, 69 (1972)

Hinkley E. D. Kelley P. L.. Science 171635 (1971)

Jensen R. J. Marinuzzi J. G. Robinson C. P. Rockwood S. D.: Laser Focus 12 $51(1976)$

Jockel, D.: Diplomarbeit, Humboldt-Universität zu Berlin 1983

JoRDAN, A. S., DERICK, L.: J. Electrochem. Soc. 116, 1424 (1969)

Kanter, Yu. O., Sidorov, Yu. G.: Izv. Akad. Nauk, Neorg. Mat. 17, 1373 (1981)

Karklina, M. I., Kovalčik T. L.: Izv. Akad. Nauk, Neorg. Mat. 4, 1344 (1968)

Kobayashi, K. L., Kato, Y., Komatsubara, K. F.: Progr. Cryst. Growth Charact. 1, $117(1978)$

Lnugter, A.. Rev. Phys. Appl, 8, 259 (1973)

Lehman n, B., Wahlen, M., Zumbrunn, R., Oeschaer, H. : Appl. Physics 13, 153 (1977)

Long, S. I., Ballantyne, J. M., Eastman, L. F.: J. Cryst. Growth 26, 13 (1974)

Melngailis, I., Harman, T. C.: in Semicond. and Semimetals 5, pp. 111, Ed. by R. K. WiLlardson and A. C. BeER; New York 1970

Mühtberg, M.: Crystal Res. \& Technol. (Kristall u. Technik) 15, 565 (1980)

MühlberG, M., Hesse, D. : phys. stat. sol. (a) 76, 513 (1983)

NiLL, K. W. : Laser Focus 13, 32 (1977)

Norr, M. K.: J. Electrochen. Soc. 109, 433 (1962)

Ohsawa, A., Honda, K., Ohkawa, S., Shinokara, K. : Appl. Phys. Lett. 37, 157 (1980)

Ohtsuki, O., Shinohara, K., Ryuzan, O.: Jap. J. Appl. Physics 10, 515 (1971)

Preier, H.: Appl. Physics 20, 189 (1979)

Strauss, A. J.: J. Electronic Mater. 2, 553 (1973)

Tiller, W. A.: in: The Art and Science of Growing Crystals, pp. 288, Ed. by J. J. GILMAN, New York 1963

Tiller, W. A.: J. Cryst. Growth 2, 69 (1968)

Tiller, W. A., Jackson, K. A., Rutter, J. W., Chalmers, B. : Acta Metallurg. 1, 428 (1953)

Tribouler, R. et al.: Proc. 4th Int. Conf. on Phys. of Narrow Gap Semicond., Linz 1981

Wagner, J. W., Willardson, R. K.: Trans. Met. Soc. AIME 242, 366 (1968)

Wolff, G. A., Mlavsky, A. I.: in: Crystal Growth, Theory and Techniques, Vol. 1, pp. 193, Ed. by C. H. L. Goodman, London-New York 1974

(Received October 27, 1983)

Author's address:

Dipl.-Krist. P. Gille, Dr. M. Mühlberg, Dipl.-Krist. L. Parthier, Doz. Dr. se. P. RuDOLPH

Humboldt-Universität zu Berlin, Sektion Physik, Bereich Kristallographie

DDR - 1040 Berlin

Invalidenstr. 43

59 Crystal Res. \& Technol., Vol, 19, No. 7 